\title{
GESTÃO DE MARCAS: UM ESTUDO SOBRE A UNIMED
}

\section{BRANDING: A STUDY ABOUT UNIMED}

\author{
Hellen Taís Zanóbio \\ Graduada em Administração pela Fundação Hermínio Ometto - Uniararas \\ Araras, SP, Brasil \\ E-mail: hzanobio@hotmail.com \\ Lariane Taína Gomes \\ Graduada em Administração pela Fundação Hermínio Ometto - Uniararas \\ Araras, São Paulo, SP, Brasil \\ E-mail: larianegomesadm@hotmail.com \\ Lilian Carolina Viana \\ Professora do Curso de Administração da Fundação Hermínio Ometto - Uniararas \\ Araras, SP, Brasil \\ E-mail: liliancviana@gmail.com \\ Lucas Silvestre de Carvalho \\ Professor do Curso de Administração da Fundação Hermínio Ometto - Uniararas \\ Araras, SP, Brasil \\ E-mail: lucas.carvalho@uniararas.br \\ Nelson Oliveira Stefanelli \\ Professor do Curso de Administração da Fundação Hermínio Ometto - Uniararas \\ Araras, SP, Brasil \\ E-mail: nelsonstefanelli@uniararas.br
}

\section{RESUMO}

O crescimento da demanda por serviços de saúde suplementar somado às mudanças da relação marca versus consumidor tornam esse mercado cada vez mais competitivo. Esses fatores implicam na movimentação das prestadoras deste tipo de serviço em relação à necessidade de identificar e implantar a melhor forma de gestão de marca, com o objetivo de torná-la conhecida e diferenciada. A empresa estudada foi a Unimed, a maior Cooperativa de Trabalho Médico do Brasil, onde se aplica o seguinte problema de pesquisa: quais as estratégias utilizadas pela Unimed na gestão de sua marca? Este estudo tem o objetivo de estudar as estratégias aplicadas pela Unimed em estudos que as exploram utilizando a metodologia de pesquisa de Revisão Bibliográfica. Os resultados obtidos foram 0 destaque da importância dada pela Unimed à gestão de sua marca onde a centraliza como diferencial competitivo, e o sucesso do uso das estratégias de gestão de marca como a identidade, imagem, personalidade, arquitetura e valor, tornando-a uma marca forte e consolidada no mercado.

Palavras-chave: Gestão de Marcas. Marca. Valor da Marca. Unimed. Prestação de Serviço.

\begin{abstract}
The growth in demand for supplemental health services added to changes in the relationship between consumer and brand make this market increasingly competitive. These factors imply the movement of providing this type of service in relation to the need to identify and implement the best branding way, in order to make it known and differentiated. The company studied was Unimed, the largest Medical Cooperative in Brazil. Thus, the research problem is stated as: what are the strategies used by Unimed in its branding? This study aims to identify the strategies applied by Unimed in using the Literature Review as research methodology. The results were the highlight of the importance given by Unimed to its branding (explored as a competitive advantage), and the successful use of branding strategies such as identity, image, character, architecture and value, making it a strong and established brand in the market.
\end{abstract}

Keywords: Branding; Brand; Brand value; Unimed; Provision of Service.

Data de aprovação: 23 de junho de 2017. 


\section{INTRODUÇÃO}

O Brasil é um país que está em constante crescimento populacional. As pesquisas do Censo realizadas em 2000 mostram que a população chegava a 169.799.170, já em 2010 a população totalizou 190.732.694 milhões de habitantes, ou seja, em 10 anos a população aumentou aproximadamente $12 \%$ (Censo 2000; 2010). Em 2025 a população brasileira chegará a 218.330.014, ou seja, a população terá um aumento de 14,5 \% em relação à população contada no Censo 2010 (IBGE, 2015).

O Instituto Brasileiro de Geografia e Estatística (IBGE) aponta que a idade média populacional está aumentando, a quantidade de pessoas com 60 anos ou mais aumentou aproximadamente $25 \%$ entre 2000 e 2010, este é um dos fatores que levaram ao aumento da demanda por serviços de saúde suplementar. Podese apontar ainda segmentos importantes para as prestadoras de serviços de saúde, compostos por identificação de riscos atribuídos à saúde, como: crianças até 10 anos, mulheres em idade fértil, sexo, grupo etário do indivíduo, pessoas com doenças crônicas, e outros. As características socioeconômicas também podem interferir na demanda de aquisição de planos de saúde sendo principalmente: idade, posição na ocupação profissional, educação, renda familiar per capita e número de componentes da família (ANDRADE; MAIA, 2007). Almeida (1998) já chamava atenção a outro fator de relevância considerável no aumento da demanda, que é a queda no nível de qualidade dos serviços públicos de saúde.

Fora a questão de demanda, a relação marca versus consumidor também exige grande atenção por parte dos gestores para constante evoluções que, altera de tempo em tempo o perfil do consumidor, forçando as empresas a dar importância à gestão da própria marca diante do mercado (MACEDO; ORLANDI, 2009).

Foi a partir do século XX que o branding e a associações de marcas tornaram-se fundamentais nas discussões gerenciais e teóricas, somado a competitividade no setor de serviços para saúde, fez com que tais negócios passassem a se preocupar mais com a gestão de sua marca (OLIVEIRA et. al, 2006), por ser base de uma forte diferenciação em relação aos concorrentes, o nome da marca para muitos representa o seu mais forte ativo, ganhando maior vantagem competitiva (AAKER, 1998).

A partir da realidade exposta, surge então a necessidade das prestadoras do serviço de saúde gerenciarem bem sua marca fazendo uso de estratégias adequadas para este segmento com o objetivo de torná-la conhecida e diferenciada perante os seus concorrentes. A empresa estudada é a maior cooperativa de trabalho médico do Brasil, a Unimed, que está no topo de consumo de saúde suplementar dominando, de acordo com Alves (2012), 83\% do território nacional e 38\% de market share. Diante desses fatos, chega-se à seguinte questão: Quais as estratégias utilizadas pela Unimed na gestão de sua marca?

O objetivo geral desta pesquisa é estudar quais as estratégias utilizadas pela Unimed na gestão de marca, e o objetivo específico é analisar cada uma destas estratégias destacando a mais eficaz. $O$ crescimento da demanda, dentre outros fatores, torna o mercado de saúde suplementar cada vez mais competitivo fazendo com que as prestadoras reconheçam a necessidade de identificar e implantar a melhor forma de gestão de sua marca. Os resultados evidenciados na pesquisa servirão como base para melhoria da gestão da marca Unimed e consequentemente o aumento do número de beneficiários. 


\section{REFERENCIAL TEÓRICO}

Este tópico aborda os conceitos dos principais temas mencionados neste estudo a fim de facilitar seu entendimento.

\section{MARCAS}

Tecnicamente a marca é um nome, termo, sinal, símbolo ou combinação dos mesmos que tem como objetivo identificar o produto, além de lembrar o consumidor de seus bens ou serviços e diferenciá-los de seus concorrentes (KOTLER, 2011), todos os seus componentes caracterizam-na como signo, que por si tem um significado e um sentido de existir (KAPFERER, 2003). Segundo Keller (1998), a origem da palavra marca (brand em inglês) vem de um antigo termo norueguês brandr, que remete à prática de marcar animais com o fogo. Essa atividade servia para indicar o proprietário do animal ou rebanho. Embora a marca remeta à um produto, é percebido como uma estratégia mais ampla no âmbito empresarial, como fonte de vantagem competitiva (KNAPP, 2002: AAKER, 1991). De modo geral, uma marca diferencia uma empresa, protegendo esta dos concorrentes que pareçam idênticos e oferencendo segurança aos consumidores. A marca sustenta, com seus atributos, o conteúdo emocional de imagens, que se constitui numa realidade econômica e social de primordial importância para dada organização (AAKER, 1998).

Para Yanase (2006) a marca constitui-se como um dos quatro tipos de bens intangíveis de uma organização, que são além desta, a imagem, o knowhow e as informações, além disso, Caputo, Macedo e Nogueira (2008) ressaltam que dentre os ativos intangíveis, ela é o mais importante. Sobre essa ótica, a marca é entendida como ativo de relacionamento, já que está em contato direto com os públicos, o que influencia positivamente o seu valor econômico, e quando encontra-se em sua maturidade são mais valorizados, proporcionando maior valor para as empresas por meio do aumento de vendas (KAYO et. al, 2006; TEH, KAYO e KIMURA, 2008). Baker (2005) corrobora ainda ao denominar a marca como ativo intangível, explicando que marcas são conglomerados funcionais e emocionais que prometem experiências exclusivas aos stakeholders.

Uma marca consolidada no mercado é um ativo de valor inestimável, pois desempenha diversas funções para as empresas que as detém. Torna-se um vínculo de confiança e sua força está nas associações que o consumidor faz quanto aos benefícios tangíveis e intangíveis que proporcionam. Para Ambler e Styles (1997) apud LOURO (2000) a marca abarca três tipos de benefícios para o consumidor, funcional, ligado a qualidade e funcionalidade de produtos ou serviços, econômicos, considerando as vantagens de custo/benefício e, psicológicos, relacionado às percepções subjetivas.

Segundo Silva (2007) a marca é responsável por indicar as qualidades do produto ou dos serviços oferecidos, bem como fortalecer sua imagem perante os consumidores. Seu valor é usado como estratégia para diferenciá-la de seus concorrentes mantendo-se no mercado e conquistando novos clientes. Além da influência no valor econômico, Keller (1998) acrescenta alguns benefícios de uma marca forte como a lealdade, menor vulnerabilidade às ações de marketing da concorrência, menor vulnerabilidade às crises de marketing, lucro maiores, dentre outros. 
Pode-se dizer que a marca é a união de atributos tangíveis e intangíveis materializados em um logotipo que gerenciados de forma adequada criam influências e geram valor para seus consumidores. Tratase de um sistema integrado que promete e entrega soluções desejadas pelas pessoas (TULESKI, 2009). A construção multidimensional da marca que visa consolidar seu conceito e traz valores emocionais e funcionais, ou seja, emoção e utilidade para atender as necessidades e vontades dos consumidores (PEREIRA, 2005), portanto, agregando às atividades estratégicas o lado do consumo simbólico (TAVARES, 2003). Para Yanase (2006) todas as ideias, sonhos e modelos de excelência encontram eco na mente, nos gostos e percepções das pessoas e as induzem a uma ação, pois as marcas marcam sua existência.

De modo geral, conclui-se que os beneficiados por uma marca bem construída são todos os presentes no mercado. Mais especificamente podendo ser separados em dois grupos: a empresa e os consumidores. A empresa como organização e todo seu pessoal, que diariamente unem esforços para realização e obtenção de resultados da marca e os consumidores potenciais (PEREIRA, 2005).

Este estudo aborda as estratégias da marca no setor de serviços onde a marca de serviço é muito parecida com uma marca de produto. Ambas servem para distinguir os produtos de uma empresa dos das outras, enquanto as marcas de serviço exercem a mesma função com relação aos serviços (OMPI Organização Mundial da Propriedade Intelectual, 2003). Neste setor, as marcas têm o papel vital de diferenciar, na mente do consumidor, as inúmeras ofertas lançadas no mercado diariamente (BARRETO, 2007).

\section{GESTÃO DE MARCAS OU BRANDING}

Gestão de marcas ou branding é o ato de dar poder a um produto ou serviço através de uma marca. Nada mais é do que criar diferenças, ensinando ao consumidor "quem" é o produto. É necessário utilizar elementos da marca para que seja fácil essa identificação, tais como saber pra que ele serve e o porquê o consumidor deva se interessar por ele (BARRETO, 2007). O objetivo do branding é diferenciar o produto ou serviço mediante seu valor, de modo a se tornar referência para o público, indo além da sua natureza econômica, ocorrendo na cultura, e influenciando a vida das pessoas (MARTINS, 2006; 2007).

Para Keller (1993) o segredo da gestão de marcas é conseguir que os clientes realmente percebam diferenças entre determinada marca e os concorrentes. Considerado ainda um sistema de ações interdisciplinares, visa o estabelecimento de imagens, percepções e associações com as quais o consumidor se relaciona. Assim sendo, o branding, nada mais é do que o criar e administrar uma marca através de todos os pontos de contato afetivo vivenciados pelo consumidor (SILVA, 2007).

Sintetizando, pode-se dizer que o branding é o conjunto de estratégias voltado ao gerenciamento do principal ativo intangível da empresa: sua marca (TULESKI, 2009). Algumas estratégias são muito utilizadas na gestão de marcas buscando igualar seu entendimento. Para Kapferer (2003) a identidade da marca é o conjunto de associações que o consumidor vai possuir em relação a marca, deve ser uma imagem sólida e pertinente a ponto de atingir a percepção pretendida (MATTAR, 2009). Segundo Kotler (2011) a identidade compreende as formas adotadas por uma empresa para identificar ou posicionar seu serviço/produto. Dessa forma, por meio da percepção do consumidor em relação à identidade da marca é que se constrói a imagem que ela vai possuir (KAPFERER, 2003). 
Para Aaker (1991) a identidade da marca é um elemento para construir a personalidade dela, por sua vez, a personalidade da marca é como um conjunto de características humanas ligadas à ela. Ou seja, a personalidade cria um relacionamento forte e, por consequência, duradouro com os consumidores, já que é a base do relacionamento entre o cliente e ela mesma. Nesse aspecto, o conceito de marca vai além da questão de diferenciação, abrangendo desde o produto até tudo aquilo que está projetado nele. Embora indiretamente, a personalidade da marca é influenciada também pelos atributos do produto, as associações de categoria, o nome e os quatro P's do mix de marketing (BATRA et. al, 1993 apud PEREIRA, 2005).

A arquitetura da marca, é a interface entre marcas e produtos ou linhas existentes no gerenciamento de marcas de uma organização (KAPFERER, 2003), ou seja, basicamente a composição do portfólio de marcas em que pode-se adicionar mais marcas para a composição do todo (SAUNDERS; GUOQUN, 1997). Para Mattar (2009), é como as marcas de uma empresa estão estruturadas e a maneira como elas se relacionam entre si. A arquitetura de marca é um componente crítico no estabelecimento de relações estratégicas e pode ser classificada de três formas: a) monolítica: onde o nome da empresa é usado em todos os produtos e serviços oferecidos; b) endossada: onde todas as submarcas estão ligadas à marca mãe verbal ou visualmente; e c) independente: onde a marca da empresa cumpre o papel de holding e cada produto ou serviço tem sua marca individual destinada para o seu mercado-alvo. Há múltiplas variações para estes três tipos de estruturas primárias, inclusive de forma híbrida (MATTAR, 2009). Assim, para Kapferer (2003), a questão são as decisões a respeito da extensão de uma marca, quando utilizar uma nova marca, quando utilizar uma marca endossada ou quando utilizar submarcas, bem como o gerenciamento destas.

A imagem da marca se trata de uma síntese da composição de impressões (verdadeiras ou imaginárias), atitudes, crenças e ideias que o público desenvolve em relação a produtos e empresas (KOTLER, 2011). Se trata então das percepções que o consumidor possui em relação a uma marca mantidas em sua memória, é refletida por associação que cada consumidor possui em sua memória. Tais associações contêm o significado que a marca remete ao seu público, se manifestando de diferentes maneiras em relação aos atributos, benefícios e às atitudes, refletindo o significado da marca mediante os consumidores (KELLER, 1993; 1998). A imagem da marca, ou posicionamento, é resultado dos esforços de marketing de uma empresa (VELOSO, 2003), que possuindo uma marca forte, obtém fonte de receitas constantes além da fidelidade do consumidor (YANASE, 2006).

Somado às essas estratégias, tem-se o valor da marca ou brand equity, segundo Louro (2000), com a percepção da importância da imagem da marca e conscientização do reflexo no seu valor, o conceito de imagem foi sendo gradualmente substituído pelo valor da marca, até mesmo pela sua amplitude. Dessa forma, o valor da marca é representado pelos ativos e passivos relacionados a uma determinada marca e a ela estão ligados a lealdade à marca, o conhecimento da marca, a qualidade percebida superior aos concorrentes, as associações da marca na mente e outros ativos da empresa que também podem fazer parte e proporcionar vantagem competitiva (AAKER, 1998). Estes resultados quando alcançados, se convertem em resultados tangíveis como o retorno do investimento feito nas propostas de marketing. Deste modo, o valor de marca pode ser negativo, quando as associações às marcas apresentam ou propõem pouca coisa (SILVA, 2007).

Especificamente relacionado às marcas de serviços, percebe-se uma importância cada vez maior, já que, devido sua característica de intangibilidade o enfoque deve ser no sentido de criar diferenciação, 
adotando-se estratégias de branding. Dessa forma, como aponta Aaker (1998) deve-se criar associações únicas para a marca a fim de estabelecer uma prioridade mediante de compra, bem como, acentuar as bases de diferenciação, o nome é essencial uma vez que outras fontes de competição são facilmente copiadas.

\section{SERVIÇOS NA ÁREA DA SAÚDE}

Serviço é qualquer ação que uma parte pode oferecer a outra e que seja principalmente intangível e não resulte na propriedade de nada. Pode estar ou não vinculada a um produto (KOTLER, 2011).

Pode ser definido como a capacidade de realização de um trabalho para alguém, no coorporativo ou

social. É totalmente humano, pois sempre envolve pelo menos uma pessoa com desejos, necessidades ou anseios (MARQUES, 2006).

Além de seu conceito próprio, possui algumas características indispensáveis para a satisfação dos desejos e necessidades do consumidor, tais como qualidade, opções e atendimento, entretanto é a marca que irá definitivamente orientar o consumidor na decisão (BARRETO, 2007).

As diferenças entre produtos e serviços são facilmente compreendidas e até mesmo administradas. Se um produto não atinge as expectativas esperadas do consumidor, é fácil localizar, identificar e avaliar o problema. Já o serviço, ao contrário, depende da interpretação de cada consumidor, que são difíceis de serem controladas, salvo se for a partir de uma estratégia de posicionamento (MARTINS, 2006).

Para a prestação de serviços na área de saúde a prestadora deve atender todas as ações necessarias à prevenção da doença, recuperação, manutenção e à reabilitação da saúde. Para atingir esses patamares, a prestadora pode: oferecer os próprios serviços, contratar/credenciar pessoas físicas ou jurídicas legalmente habilitadas e na ausencia desse credenciamento, deve reembolsar o beneficiario (LIMA, 2005).

A utilização dos serviços é o núcleo do sistema de saúde, pois sem ele não há funcionamento. $O$ conceito de uso compreende diretamente consultas médicas e hospitalizações e indiretamente realização de exames preventivos e diagnósticos. O processo de utilização dos serviços de saúde é a relação do individuo que busca cuidados com o profissional que os oferece (TRAVASSOS; MARTINS, 2004).

\section{METODOLOGIA DE PESQUISA}

A metodologia usada para o desenvolvimento da pesquisa foi a revisão de literatura que para Acevedo e Nohara (2009) se trata de revisões de estudos anteriores, respaldando a investigação em relação aos métodos e técnicas utilizados para empreender a pesquisa. É a etapa do trabalho que permite ao autor se aprofundar sobre o objeto de estudo, e tem como consequência o maior entendimento sobre o problema.

Este trabalho orienta-se para uma pesquisa descritiva de caráter qualitativo, uma vez que trabalha com significados, motivos, aspirações, crenças, valores e atitudes. O tipo escolhido para a pesquisa foi o descritivo. A pesquisa descritiva expõe as características de determinada população ou fenômeno, estabelece correlações entre variáveis e define sua natureza. A conclusão sobre a modalidade da pesquisa descritiva é aquela que objetiva descrever ou definir determinado fenômeno, em que o pesquisador observa, registra, analisa, classifica e interpreta os fatos (VERGARA, 2005; MALHOTRA, 2001). 
A revisão de literatura foi realizada com duas bases de coletas distintas. A primeira etapa foi constituída pela coleta de artigos, teses, monografias e dissertações pesquisados na plataforma "Google Acadêmico" buscando as estratégias específicas de gestão de marcas da Unimed, seguindo os parâmetros descritos a seguir:

- Palavra-chave da busca: Gestão da marca Unimed.

- Idioma: Português.

- Relevância: publicações que atendem o objetivo do estudo.

Nesta fase foram selecionados 12 estudos conforme Quadro 1.

Quadro 1. Estudos sobre as aplicações das Estratégias de Branding na Unimed

\begin{tabular}{|c|l|}
\hline Assuntos abordados & Autor/Ano \\
\hline Identidade da Marca & $\begin{array}{l}\text { Grinberg (2001); Duarte (2001); Padula (2004); Oliveira et al (2006); Schimitt (2007); Fonseca } \\
\text { (2008); Younes (2009); Macedo e Orlandi (2009); Locatelli (2013) e Born et al (2014). }\end{array}$ \\
\hline Imagem da Marca & $\begin{array}{l}\text { Grinberg (2001); Padula (2004); Oliveira et al (2006); Schimitt (2007); Toledo (2007); Fonseca } \\
\text { (2008); Younes (2009); Macedo e Orlandi (2009); Locatelli (2013) e Born et al (2014). }\end{array}$ \\
\hline $\begin{array}{c}\text { Personalidade da } \\
\text { Marca }\end{array}$ & $\begin{array}{l}\text { Grinberg (2001); Oliveira et al (2006); Fonseca (2008); Younes (2009); Macedo e Orlandi } \\
\text { (2009) e Locatelli (2013). }\end{array}$ \\
\hline $\begin{array}{c}\text { Arquitetura da Marca } \\
\text { Valor da Marca }\end{array}$ & $\begin{array}{l}\text { Grinberg (2001); Duarte (2001); Padula (2004); Oliveira et al (2006); Toledo (2007); Fonseca } \\
\text { (2008); Younes (2009); Locatelli (2013) e Born et al (2014). } \\
\text { (2008); Younes (2009); Macedo e Orlandi (2009); Resende et al (2012; Alves (2012); Locatelli } \\
\text { (2013) e Born et al (2014). }\end{array}$ \\
\hline
\end{tabular}

Fonte: Elaborado pelos autores.

A segunda etapa foi constituída pela coleta de artigos, teses, monografias e dissertações pesquisados na plataforma de periódicos da CAPES (Coordenação de Aperfeiçoamento de Pessoal de Nível Superior) buscando as estratégias gerais de gestão de marcas, conforme Quadro 2, seguindo os parâmetros descritos a seguir:

- Período: publicações do ano de 2010 a 2014 por serem estudos atuais.

- Palavras-Chave: Identidade da marca, Imagem da marca, Personalidade da marca, Arquitetura da marca, Valor da marca.

- Idioma: Português

- Relevância: publicações que atendem o objetivo do trabalho.

- Qualificação: de A1 a B5 para os artigos publicados em revistas.

Nesta fase foram selecionados 29 estudos conforme Quadro 2. 


\section{Quadro 2. Estudos sobre as Estratégias de Branding}

\begin{tabular}{|c|c|}
\hline Assuntos abordados & Autor/Ano \\
\hline Identidade da Marca & $\begin{array}{l}\text { Miquelino, Santos e Padovani (2004); Brito (2010); Garrán (2010); Gonçalves, Garrido e } \\
\text { Damacena (2010); Thomaz e Brito (2010); Castanheira e Coelho (2011); Hernandez et al } \\
\text { (2011); Mager (2011); Nascimento, Nunes e Basto (2011); Parisotto (2011); Pereira e Cabral } \\
\text { (2011); Scharf (2011); Assis, Cardoso e Serralvo (2012); Consolo (2012); Dal Bó, Milan e De } \\
\text { Toni (2012); Mariutti (2012); Sant'anna (2012); Bararndas (2013); Coelho (2013); D' Emídio, } \\
\text { Rocha e D' Emídio (2013); Lima e Baptista (2013); Lopes e Hernandez (2013); Ramos (2013); } \\
\text { Souza e Leão (2013); Leão et al (2014); Pizzinatto et al (2014); Semprebon et al (2014). }\end{array}$ \\
\hline Imagem da & $\begin{array}{l}\text { Miquelino, Santos e Padovani (2004); Brito (2010); Garrán (2010); Gonçalves, Garrido e } \\
\text { Damacena (2010); Thomaz e Brito (2010); Castanheira e Coelho (2011); Hernandez et al } \\
\text { (2011); Mager (2011); Nascimento, Nunes e Basto (2011); Parisotto (2011); Pereira e Cabral } \\
\text { (2011); Scharf (2011); Assis, Cardoso e Serralvo (2012); Consolo (2012); Dal Bó, Milan e De } \\
\text { Toni (2012); Mariutti (2012); Bararndas (2013); Coelho (2013); D' Emídio, Rocha e D' Emídio } \\
\text { (2013); Lima e Baptista (2013); Lopes e Hernandez (2013); Ramos (2013); Souza e Leão } \\
\text { (2013); Leão et al (2014); Pizzinatto et al (2014); Semprebon et al (2014). }\end{array}$ \\
\hline $\begin{array}{l}\text { Personalidade da } \\
\text { Marca }\end{array}$ & $\begin{array}{l}\text { Miquelino, Santos e Padovani (2004); Brito (2010); Garrán (2010); Gonçalves, Garrido e } \\
\text { Damacena (2010); Thomaz e Brito (2010); Castanheira e Coelho (2011); Hernandez et al } \\
\text { (2011); Mager (2011); Nascimento, Nunes e Basto (2011); Parisotto (2011); Pereira e Cabral } \\
\text { (2011); Scharf (2011); Assis, Cardoso e Serralvo (2012); Consolo (2012); Dal Bó, Milan e De } \\
\text { Toni (2012); Mariutti (2012); Bararndas (2013); Coelho (2013); Lopes e Hernandez (2013); } \\
\text { Ramos (2013); Souza e Leão (2013); Leão et al (2014); Pizzinatto et al (2014); Semprebon } \\
\text { et al (2014). }\end{array}$ \\
\hline Arquitetura da Marca & $\begin{array}{l}\text { Miquelino, Santos e Padovani (2004); Brito (2010); Garrán (2010); Gonçalves, Garrido e } \\
\text { Damacena (2010); Thomaz e Brito (2010); Castanheira e Coelho (2011); Hernandez et al } \\
\text { (2011); Mager (2011); Nascimento, Nunes e Basto (2011); Oliveira e Luce2011); Parisotto } \\
\text { (2011); Pereira e Cabral (2011); Scharf (2011); Assis, Cardoso e Serralvo (2012); Consolo } \\
\text { (2012); Dal Bó, Milan e De Toni (2012); Mariutti (2012); Sant'anna (2012); Bararndas (2013); } \\
\text { Coelho (2013); D' Emídio, Rocha e D' Emídio (2013); Lima e Baptista (2013); Lopes e } \\
\text { Hernandez (2013); Ramos (2013); Souza e Leão (2013); Leão et al (2014); Pizzinatto et al } \\
\text { (2014); Semprebon et al (2014). }\end{array}$ \\
\hline Valor da Marca & $\begin{array}{l}\text { Miquelino, Santos e Padovani (2004); Brito (2010); Garrán (2010); Gonçalves, Garrido e } \\
\text { Damacena (2010); Thomaz e Brito (2010); Castanheira e Coelho (2011); Hernandez et al } \\
\text { (2011); Mager (2011); Nascimento, Nunes e Basto (2011); Oliveira e Luce2011); Parisotto } \\
\text { (2011); Pereira e Cabral (2011); Scharf (2011); Assis, Cardoso e Serralvo (2012); Consolo } \\
\text { (2012); Dal Bó, Milan e De Toni (2012); Mariutti (2012); Bararndas (2013); Coelho (2013); D' } \\
\text { Emídio, Rocha e D' Emídio (2013); Lima e Baptista (2013); Lima et al (2013); Lopes e } \\
\text { Hernandez (2013); Ramos (2013); Souza e Leão (2013); Leão et al (2014); Pizzinatto et al } \\
\text { (2014); Semprebon et al (2014). }\end{array}$ \\
\hline
\end{tabular}

Fonte: Elaborado pelos autores.

Com base no material levantado nas duas etapas, foi feita uma análise comparativa, que para Fachin (2006) é o ato investigatório de fatos, segundo suas semelhanças e diferenças a fim de detectar o que é comum aos dois. Esse método foi usado para comparar as estratégias de gestão da marca utilizadas pela 
Unimed descritas no Quadro $1 \mathrm{com}$ as expostas na teoria descritas no Quadro 2 apresentadas no tópico resultados e discussão sendo essas estratégias: a identidade, imagem, personalidade, arquitetura e valor da marca.

\section{RESULTADOS E DISCUSSÃO}

\section{A empresa}

O complexo empresarial cooperativo Unimed nasceu na cidade de Santos no estado de São Paulo, no dia 18 de dezembro de 1967, fundado por Edmundo Castilho. Essa fundação foi o marco do cooperativismo do trabalho médico no Brasil (DUARTE, 2001; ALVES 2012).

A Unimed como um todo detém mais de 367 cooperativas, mais de 111 mil médicos cooperados, 104 hospitais próprios, 3067 hospitais credenciados, 69 mil empregos diretos, 290 mil empregos indiretos, 18 milhões de clientes e um faturamento conjunto de $\mathrm{R} \$ 30,1$ bilhões, a Unimed está presente em $83 \%$ do território nacional, com market share de 38\% (MACEDO; ORLANDI, 2009; ALVES, 2012).

\section{Estudos Encontrados e Discussão}

Os resultados obtidos, a partir do problema de pesquisa exposto, apontam para o uso das estratégias de branding na Unimed, sendo elas: identidade, imagem, personalidade, arquitetura e valor da marca. $\mathrm{Na}$ análise foi utilizado o método comparativo entre as abordagens apresentadas pelos autores versus a aplicação das mesmas na Unimed, fazendo isso individualmente em cada estratégia. Com base na análise foi detectado que há coerência entre elas, pois os autores citados no Quadro 2, em que são apresentados as estratégias de branding e os autores/ano, convergem com as aplicações dessas estratégias na Unimed citados pelos autores/ano descritos no Quadro 1, ou seja, existe coerência plena entre teoria e aplicação destacando, inclusive, o uso da mesma abordagem para os assuntos tratados.

\section{Identidade da Marca}

De acordo com Macedo e Orlandi (2009), a gestão da Unimed se preocupou em fazer um diagnóstico detalhado sobre o emprego e identidade visual da marca Unimed. Com essa investigação descobriu-se que havia mais de duas mil formas de utilização, ou seja, a identidade e seus valores estavam se perdendo com o tempo. Preocupada com isso, foi reformulado os critérios de uso e utilização da marca para todas as cooperativas. A letra "U" passou a ser maiúscula para melhor percepção do consumidor, e foi incorporada uma barra para separar a marca do local onde ela opera ou dos produtos e serviços que oferece.

A identidade visual da Unimed, ou logo, tem o intuito de diferenciá-la perante a concorrência através da uniformidade e a conformidade, ou seja, o sistema todo é representado como se fosse um só, além de promover sua filosofia de prevenção à saúde e qualidade de vida (MACEDO; ORLANDI, 2009). Com base nos autores estudados descritos no Quadro 2 que abordam o assunto, o tema identidade da marca abrange a organização como um todo incluindo estrutura física, desempenho do serviço prestado e sua marca como 
identidade visual. Esta deve ser apresentada de forma imutável para se tornar única, ou seja, quando o consumidor a visualizar associe a empresa em questão. A percepção da identidade pode ser não apenas visual, ela pode ser percebida através de sons, aromas, sentimentos etc. A identidade bem estruturada reflete positivamente na imagem da marca. Segundo o Quadro 1, nota-se que a Unimed adotou uma estratégia para deixar claro que o principal objetivo é ser reconhecida pelo consumidor como a melhor empresa na área de saúde suplementar através da obtenção de uma identidade sólida, única e integrada em nível nacional.

\section{Imagem da Marca}

Considerando que a imagem é a percepção do consumidor, a Unimed comprova através de premiações obtidas que sua imagem é positiva, a marca é Top of Mind pela $19^{a}$ vez e líder isolada (YOUNES, 2009).

De acordo com Fonseca (2008), a marca Unimed foi eleita, por 11 vezes consecutivas, como o plano de saúde em que os brasileiros mais confiam na Pesquisa Marcas de Confiança conduzida pela Revista Seleções/Instituto Marplan no Brasil. Obteve o prêmio Top Performance, como a marca de melhor desempenho entre as diversas empresas concorrentes em 40 categorias. Detentora também do prêmio Mérito Lojista por 23 vezes consecutivas como o plano de saúde preferido de sócios da Confederação dos Dirigentes Lojistas. Segundo os autores estudados descritos no Quadro 2, imagem da marca é a percepção da identidade da marca pelo consumidor, ou seja, a identidade é o que a empresa quer passar e a imagem é o que o consumidor percebe. Ela deve ser coerente com a identidade e transmitir os valores que quer passar aos clientes, bem como sua personalidade, além de induzir sensações. Isso pode acontecer de maneira negativa, quando a imagem é percebida de maneira diferente do que a identidade. A imagem é consequência de sua identidade juntamente com a relação marca x consumidor. É importante frisar que a imagem será construída de qualquer maneira, por isso, a empresa deve se preocupar em construir/criar uma identidade que reflita uma imagem positiva. Conforme os autores estudados descritos no Quadro 1, a imagem da Unimed perante os consumidores reflete no que a empresa trabalha em sua identidade, pois as premiações conquistadas comprovam que a identidade remete uma imagem positiva na mente do consumidor e como consequência é a mais lembrada.

\section{Personalidade da Marca}

Ao se falar em personalidade da marca, de acordo com Macedo e Orlandi (2009), o patrocínio ao esporte é um exemplo de ação em que a Unimed sempre esteve presente. Seu apoio abrange várias categorias esportivas além de ser o plano de saúde oficial da Equipe Paraolímpica, desde 2004. Há, portanto, uma orientação nacional de vinculação da marca Unimed à saúde, ao esporte, à qualidade de vida e à responsabilidade social.

Segundo Younes (2009) a Unimed se empenha em contribuir com a sociedade por meio da participação e criação de programas de responsabilidade social e ambiental como, por exemplo, o uso consciente de papel, água e luz e uso de papel ecologicamente correto. 
Com base nos autores estudados descritos no Quadro 2, que abordam o tema no assunto, a personalidade é o conjunto de atribuições que uma pessoa teria incorporada à marca, ou seja, seu comportamento, sentimentos, etc. A marca então é responsável pela criação de vínculo com o consumidor. Com base no Quadro 1, nota-se que a Unimed se preocupa em transferir aos consumidores uma personalidade de responsabilidade social e ambiental, solidária e preocupada com o bem-estar e a qualidade de vida.

\section{Arquitetura da Marca}

No sentido de arquitetura da marca, a Unimed dispõe sua marca de maneira monolítica para o setor de saúde suplementar, que abrange a Confederação, as Federações e as Singulares dispostas no território nacional. Essa disposição é vista pelo consumidor como única, porém, é formada pela união de várias cooperativas separadas que atendem um mesmo parâmetro designado pela Confederação. Além do que, se dispõe de maneira híbrida para as extensões da marca/categoria, como por exemplo, as empresas que levam o seu nome, ou a lembrança dele como Unicred, Usimed, Unimed Odonto, Unimed Seguros, Unimed Sistemas etc. (PADULA, 2004).

Segundo Duarte (2001), o crescimento acelerado das cooperativas de trabalho médico Unimed, assim como as condições do mercado cada vez mais competitivas, mostrou a necessidade de criar instituições e empresas para apoiá-las, fazendo parte de sua arquitetura, sendo elas: Unimed Seguros, Unimed Sistemas, Unicred e Unimed Odonto. Segundo os autores estudados descritos no Quadro 2 que abordam o tema, arquitetura é a disposição das marcas organizada esquematicamente para melhor visualização da oferta total pela marca mãe. Através desse esquema é possível prever ações, evoluções e gerenciar a introdução de novos produtos/serviços. A relação que a marca mãe mantém com as demais influenciam na imagem da organização, ou seja, se a imagem da marca mãe for positiva, vai refletir em outras marcas dispostas na mesma estrutura. De acordo com o Quadro 1 a Unimed possui uma arquitetura bem estruturada, em que há uniformidade de estrutura física, atendimento e serviços quando se tratam do mesmo segmento fazendo com que o consumidor se sinta como se fosse uma única empresa. Deve-se levar em consideração que o sucesso da Unimed interferirá nas demais, tanto nas singulares e federações quanto nas empresas de apoio.

\section{Valor da Marca ou Brand Equity}

A força da marca Unimed é conhecida e reconhecida e destacada como seu principal diferencial competitivo. Segundo a Brand Finance Consultoria, a Unimed foi a $29^{\mathrm{a}}$ marca mais valiosa do país no ano de 2012, com valor estimado em $R \$ 3,22$ bilhões (ALVES, 2012). Segundo autores citados no Quadro 2, o valor da marca está relacionado à percepção emocional do consumidor. Essa percepção depende das ações positivas que a empresa empenha na gestão de sua marca e o quanto isto agrega ao seu público. $O$ valor da marca é o resultado positivo obtido através das demais ações de branding denominadas como identidade, imagem, personalidade e arquitetura de marca. Segundo os autores do Quadro 1 que tratam o assunto, as boas gestões das estratégias de branding utilizadas pela Unimed, identidade, imagem, personalidade e arquitetura da marca, agregam valor afetivo na relação da marca com o consumidor onde esse afeto conta 
mais na aquisição do serviço do que as próprias características intrínsecas. Tudo isso incide na valorização monetária da marca.

\section{CONSIDERAÇÕES FINAIS}

A partir do problema de pesquisa e objetivos definidos, pode-se concluir que a Unimed usa diversas estratégias de branding na gestão de sua marca, identidade, imagem, personalidade, arquitetura e valor da marca. Isso implica em uma marca forte e diferenciada num mercado altamente competitivo. Ressalta-se que a Unimed está há 30 anos liderando o mercado, e feito um forte trabalho na gestão da marca em nível nacional. A centralização na gestão estratégica da Unimed traz conformidade e unicidade para a marca em todo o sistema. A boa gestão da marca se dá através do sucesso na utilização das estratégias de branding. A identidade da marca trata o institucional da organização, ou seja, como a Unimed quer ser vista no mercado, o foco atual é a sua identidade visual. A imagem da marca Unimed é a resposta positiva de sua identidade. Mostra-se através dos prêmios ganhos como marca e instituição concedidos pela percepção do público alvo e outras entidades. Sua personalidade é responsável socialmente, ambientalmente e solidária, voltada para ações de bem estar e qualidade de vida. Essa personalidade é expressa ao público através de patrocínios, projetos sustentáveis e programas sociais. A arquitetura da marca Unimed é híbrida, pois há várias caracterizações de sua marca dentro do sistema, em que podem ser tanto monolíticas, independentes e endossadas.

Portanto, identifica-se como reflexos de uma marca híbrida, aplicando as evidências da marca Unimed, maior reconhecimento pelo consumidor devido a extensão de marca adotada neste caso, por consequência o maior valor, já que se expande o valor de marca para o conjunto híbrido adotado. A vantagem de estabelecer uma marca híbrida fica relacionada então ao maior conhecimento pelo consumidor o que garante uma marca forte e a garantia de ganhos futuros.

O sucesso dessas estratégias juntas tende a agregar valor à marca, inicialmente afetivo e ao longo do tempo econômico aumentando o ativo da empresa, sendo o Valor da Marca como estratégia adequada, já que o resultado positivo da boa gestão de todas as marcas é o que remete a marca à mente do consumidor.

A principal limitação foi a mensuração das estratégias de branding, levando em consideração que elas são interligadas e na maioria das vezes são difíceis de serem identificadas individualmente necessitando de um estudo que faça a apuração de modelos que possam mensurar. Os resultados obtidos contribuirão para comprovar que a Unimed gere muito bem sua marca para gestores da área e estudantes do tema, além de servir como base para estudos futuros. Teoricamente, é ingrediente para valorizar os aspectos relacionados à marca e ao branding reforçando a importância de se trabalhar tal área na gestão. Os resultados também são essenciais para a prestação desse tipo de serviço que possui uma relação tão sensível com o consumidor, mostrando o quanto as prestadoras de serviços precisam se aproximar dos clientes.

Sugerem-se estudos futuros para cada uma das estratégias de maneira mais profunda ainda usando a metodologia de revisão bibliográfica para um melhor entendimento de cada uma delas e, o mesmo estudo apresentado fazendo uso de uma nova metodologia, sendo ela a entrevista e a observação participativa, levando em consideração que este estudo foi realizado para a marca em nível nacional a sugestão do novo estudo seria para o relacionamento de cada uma das unidades regionais. 


\section{REFERÊNCIAS}

AAKER, D. A.; Marcas: Brand Equity gerenciando o valor da marca. São Paulo: Negócio, 1998.

AAKER, D. A. Managing Brand Equity: Capitalizing on the Value of a Brand Name. New York: The Free Press, 1991.

ACEVEDO, C. R.; NOHARA, J. J. Monografia no curso de administração. $3^{a}$ ed. São Paulo: Atlas, 2009.

ALMEIDA, C. O mercado privado de serviços de saúde no Brasil: Panorama atual e tendências da assistência médica suplementar. Brasília, 1998. Disponível em: http://www.ipea.gov.br/agencia/images/stories/PDFs/TDs/td_0599.pdf. Acesso em: 30 mar. 2015.

ALVES, M. F.; CARVALHO, W. C. de. O intercâmbio nacional como base de vantagem competitiva para o Sistema Unimed: Um recurso estratégico. 2012. 28 f. Monografia (Especialização) - Curso de Gestão de Negócios de Saúde, Faculdade de Ciencias Medicas de Minas Gerais, Belo Horizonte, 2012. Disponível em: <file:///C:/Users/pesquisa06/Documents/Downloads/MARCIONIS FRANCISCO ALVES.pdf>. Acesso em: 31 mar. 2015.

ANDRADE, M. V.; MAIA, A. C. Demanda por planos de saúde no Brasil. Rio de Janeiro: IPEA, 2007. Disponível em: http://www.ipea.gov.br/agencia/images/stories/PDFs/livros/15_Cap08.pdf. Acesso em: 30 mar. 2015.

ASSIS, E. E.; CARDOSO, O. O.; SERRALVO, F. A. O processo de construção de uma marca. Organizações em Contexto, São Bernardo do Campo, v. 08, n. 15, p.179-197, jun. 2012. Disponível em:

<https://www.metodista.br/revistas/revistas-ims/index.php/OC/article/viewArticle/3115>. Acesso em: 28 mar. 2015.

BAKER , M. J. Administração de Marketing. Rio de Janeiro: Elsevier, 2005.

BARANDAS, C. P. Brand Equity: um caso de estudo do amor às marcas Apple e Samsung. 2013. 95 f. Dissertação (Mestrado) - Curso de Marketing, Universidade de Coimbra, Coimbra, 2013. Disponível em:

<https://estudogeral.sib.uc.pt/bitstream/10316/24788/1/Tese Versão Final Barandas.pdf>. Acesso em: 15 mar. 2015.

BARRETO, M. A Importância da Marca para as Empresas de Serviços. Global Manager (FSG), v. 15, p. 137-153, 2008. Disponível em: http://www.portal-rp.com.br/bibliotecavirtual/outrasareas/ marketing01/0330.pdf. Acesso em: 28 mar. 2015

BÓ, G. dal; MILAN, G. S.; TONI, D. de. O endosso por celebridade e a gestão da imagem da marca: evidências empíricas a partir do estudo da marca Ipanema Gisele Bündchen. Read, Porto Alegre, v. 3, n. 73, p.681-717, dez. 2012. Disponível em: <http://www.scielo.br/pdf/read/v18n3/v18n3a05.pdf>. Acesso em: 15 mar. 2015.

BORN, A. et al. Interatividade em Mídias Tradicionais: Uma analise do percurso gerativo de sentido na campanha "Unimed - o plano único". Intercom: XV Congresso de Ciências da Comunicação na Região Sul, Palhoça, p.1-11, maio 2014. Disponível em: <http://www.portalintercom.org.br/anais/sul2014/resumos/R40-1025-1.pdf>. Acesso em: 01 abr. 2015.

BRITO, C. Uma abordagem relacional ao valor da marca. Revista Portuguesa e Brasileira de Gestão, Campo Grande, v. 9, n. 1-2, p.49-63, jun. 2010. Disponível em: <http://www.scielo.mec.pt/pdf/rpbg/v9n1-2/v9n1-2a06.pdf>. Acesso em: 15 mar. 2015.

CAPUTO, E. S., MACEDO, M. A. da S., NOGUEIRA, H. G. P. Avaliação de marcas: uma aplicação ao caso Bombril. RAE eletrônica, v. 7, n. 2, 2008.

CASTANHEIRA, J. C. S.; COELHO, J. A. Dos sinos ao Ipod: sons, espaços e identidades nas novas estratégias das marcas. Comunicação, Mídia e Consumo, São Paulo, v. 9, n. 25, p.219-239, ago. 2012. Disponível em: <http://revistacmc.espm.br/index.php/revistacmc/article/view/320/pdf>. Acesso em: 15 mar. 2015.

COELHO, A. R. M. Semiótica da marca: Contributos para a construção de uma sintaxe e retórica visual para a prática do design da identidade. 2013. 245 f. Tese (Doutorado) - Curso de Design de Comunicação, Universidade do Porto, Porto, 2013. Disponível em: <http://repositorio-

aberto.up.pt/handle/10216/71966?mode=full\&submit_simple=Mostrar+registo+em+formato+completo>. Acesso em: 15 mar. 2015.

CONSOLO, M. C. Marcas a expansão simbólica da identidade: origem da metodologia projetual das marcas corporativas e revisão dos métodos de implantação dos sistemas de uso. 2012. 224 f. Tese (Doutorado) - Curso de Ciências da Comunicação, Universidade de São Paulo, São Paulo, 2012. Disponível em:

<http://www.teses.usp.br/teses/disponiveis/27/27154/tde-22052013-115558/pt-br.php>. Acesso em: 15 mar. 2015.

D`EMIDIO, M.; ROCHA, T. V.; D`EMIDIO, M. G. N.. O cálculo do valor da marca por consumidores: estudo empírico no setor de telefonia móvel. Rege, São Paulo, v. 20, n. 4, p.517-535, dez. 2013. Disponível em:

<http://www.spell.org.br/documentos/ver/30642/o-calculo-do-valor-da-marca-por-consumidores--e--->. Acesso em: 27 mar. 2015.

DUARTE, C. M. R.. Unimed: História e características da cooperativa de trabalho médico no Brasil. Caderno de Saúde Pública, Rio de Janeiro, v. 4, n. 17, p.999-1008, ago. 2001. Disponível em: <http://www.arca.fiocruz.br/bitstream/icict/9766/1/5306.pdf>. Acesso em: 31 mar. 2015.

ESTRELA, C. Metodologia Científica. 2a edição. São Paulo: Artes Médicas, 2005. 
FACHIN, O. Fundamentos de Metodologia. $5^{a}$ edição. São Paulo: Saraiva, 2006.

FONSECA, C. Unimed: 40 anos de cooperativismo médico no Brasil. $1^{\text {a }}$ edição. São Paulo: Museu da Pessoa, 2008.

GARRAN, V. G. Cultura e posicionamento internacional de marcas de serviços. 2010. 308 f. Tese (Doutorado) - Curso de Administração, Universidade de São Paulo, São Paulo, 2010. Disponível em:

<http://www.teses.usp.br/teses/disponiveis/12/12139/tde-27082010-110845/pt-br.php>. Acesso em: 15 mar. 2015.

GIL, A. C. Como elaborar projetos de pesquisa. 5a edição. São Paulo: Atlas, 2010.

GODOY, Arilda Schimidt. Pesquisa Qualitativa: tipos fundamentais. Revista de Administração de Empresas. v.35, n.3, p, 20-29. São Paulo. Maio/Junho 1995. Disponível em: http://www.scielo.br/pdf/rae/v35n3/a04v35n3.pdf. Acesso em: 28 mar. 2015.

GONÇALVES, L. C. D.; GARRIDO, I. L.; DAMACENA, C. Proposta de um modelo conceitual de valor de marca na nova lógica de serviços. Revista Brasileira de Gestão de Negócios, São Paulo, v. 12, n. 36, p.341-357, set. 2010. Disponível em: <http://www.spell.org.br/documentos/ver/6610/proposta-de-um-modelo-conceitual-de-valor-de-ma--->. Acesso em: 31 mar. 2015

GRINBERG, C. S; LUCE, F. B. Marketing Metrics: Um estudo exploratório sobra a construção do conhecimento de um novo tema em marketing. 2001. 125 f. Dissertação (Mestrado) - Curso de Administração, Universidade Federal do Rio Grande do Sul, Porto Alegre, 2001. Disponível em:

<http://www.lume.ufrgs.br/bitstream/handle/10183/2026/000313330.pdf?sequence=1\&locale=pt_BR>. Acesso em: 31 mar. 2015.

HERNANDEZ, J. M. da C. et al. Extensão de marcas corporativas de serviços: O efeito da similaridade percebida da extensão e da qualidade percebida da marca. Rac, Curitiba, v. 15, n. 4, p. 561 - 579, ago. 2011. Disponível em: http://www.scielo.br/pdf/rac/v15n4/a02v15n4.pdf. Acesso em: 01 mar. 2015.

IBGE, Instituto Brasileiro de Geografia e Estatística, 2015. Disponível em:

http://saladeimprensa.ibge.gov.br/noticias?view=noticia\&idnoticia=2455. Acesso em: 04 mar. 2015.

IBGE. Instituto Brasileiro de Geografia e Estatística Censo 2000. Disponível em:

http://www.ibge.gov.br/home/estatistica/populacao/censo2000/tabelabrasil111.shtm. Acesso em: 04 mar. 2015.

IBGE. Instituto Brasileiro de Geografia e Estatística Censo 2010. Disponível em:

http://www.ibge.gov.br/home/estatistica/populacao/censo2010/default.shtm. Acesso em: 04 de março de 2015.

KAPFERER,J. N. As marcas capital da empresa: criar e desenvolver marcas fortes. Trad. Arnaldo Ryngelbulum.-3, Ed,Porto Alegre :Bookman, 2003.

KAYO, E. K. et al. Ativos intangíveis, ciclo de vida e criação de valor. Revista de Administração Contemporânea, Curitiba, v. 10, n. 3, p. 73-90, 2006. Disponível em http://www.scielo.br/scielo.php?script=sci_arttext\&pid=S1415$65552006000300005 \&$ Ing=en\&nrm=iso. Acesso em 29 de maio de 2017.

KELLER, K. L. Conceptualizing, measuring and managing customer: based brand equity. Journal of Marketing. v. 57 , n. 1, p. 1-22, 1993.

Keller, K. L. Strategic brand management: building, measuring, and managing brand equity. New Jersey: Prentice Hall, 1998.

KNAPP, D. E. Brandmindset: Fixado a marca. Rio de Janeiro: Qualitymark, 2002.

KOTLER, Phillip. Administração de marketing: análise, planejamento, implementação e controle. $5^{\mathrm{a}}$ edição. São Paulo: Atlas, 2011.

LEÃO, A. L. M. de S. et al. Avaliação da personalidade da marca Pague menos na ótica dos clientes. Reen, Florianópolis, v. 7, n. 3, p.256-276, dez. 2014. Disponível em:

<http://www.portaldeperiodicos.unisul.br/index.php/EeN/article/view/2141/1965>. Acesso em: 30 mar. 2015.

LIMA, A. de A. de et al. Marcas de perfumes simbólicas na percepção das consumidoras. Rege, São Paulo, v. 20, n. 2, p.251-265, jun. 2013. Disponível em: <http://www.revistas.usp.br/ rege/article/view/62038>. Acesso em: 30 mar. 2015.

LIMA, A. de A. de; BAPTISTA, P. de P. Impacto da congruência entre autoconceito e personalidade de marca na intensidade da qualidade de relacionamento e lealdade do consumidor. Remark, São Paulo, v. 12, n. 1, p.73-96, mar. 2013. Disponível em: <http://www.more.ufsc.br/artigo_revista/ inserir_artigo_revista>. Acesso em: 28 mar. 2015.

LIMA, C. R. M. de. Administração da assistência suplementar à saúde. E-papers, Rio de Janeiro, 2005.

LOCATELLI, F. E.. Comunicação Organizacional e ofertas de imagem-conceito: a Unimed Poa em seu blog IBE. 2013. 79 f. TCC (Graduação) - Curso de Comunicação Social, Universidade Federal do Rio Grande do Sul, Porto Alegre, 2013. Disponível em: <http://www.lume.ufrgs.br/bits tream/handle/10183/77984/000898279.pdf?sequence=1\&locale=pt_BR>. Acesso em: 15 mar. 2015. 
LOPES, E. L.; HERNANDEZ, J. M. C. Percepção da estratégia de extensão de marca em estabelecimentos comerciais: qual o melhor nome para uma loja? Reen, Santa Catarina, v. 6, n. 1, p.108-133, abr. 2013. Disponível em: <https://www.portaldeperiodicos.unisul.br/ojs/index.php/ EeN/article/view/899>. Acesso em: 28 mar. 2015.

LOURO, M. J. S. Modelos de Avaliação de Marca. RAE - Revista de Administração de Empresas. São Paulo, Abr./Jun., v. 40 , n. 2 , p. $26-37,2000$.

MACEDO, R. G.; ORLANDI, R. G. Impactos mercadológicos na gestão de marcas para comunicação com público consumidor: Uma análise do Sistema Nacional Unimed.2009. Disponível em:

http://www2.metodista.br/unesco/1_Regiocom\%202009/arquivos/trabalhos. Acesso em: 15 mar. 2015.

MAGER, G. B. Havaianas, por que todo mundo usa? O espaço social da marca e o design na contemporaneidade. 2011. 236 f. Tese (Doutorado) - Curso de Design, Pontifícia Universidade Católica, Rio de Janeiro, 2011. Disponível em: <http://www2.dbd.puc-rio.br/pergamum/tesesabertas/0721267_2011>. Acesso em: 31 mar. 2015.

MALHOTRA, N. K. Pesquisa de marketing: uma orientação prática. $6^{a}$ ed. Porto Alegre, 2001.

MARIUTTI, F. G.. Identidade de marca-país: Comunicação da marca país nos Estados Unidos da América. 2012. 232 f. Dissertação (Mestrado) - Curso de Administração de Organizações, Universidade de São Paulo, Ribeirão Preto, 2012. Disponível em: <http://www.teses.usp.br/teses/ disponiveis/96/96132/tde-04052012-113333/pt-br.php>. Acesso em: 15 mar. 2015

MARQUES, F. Guia prático de excelência em serviços: como conquistar clientes, aumentar lucros e viver melhor! São Paulo: Nobel, 2006.

MARTINS, J. R.. Branding: O Manual para você criar, gerenciar e avaliar marcas. $3^{\text {a }}$ edição. São Paulo: Atlas, 2006.

MARTINS, J. S. A natureza emocional da marca: construção de empresas ricas. Rio de Janeiro: Elsevier, 2007.

MATTAR, F. N. (Org.). Gestão de produtos, serviços, marcas e mercados: estratégias e ações para alcançar e manterse top of market. São Paulo: Atlas, 2009.

MIQUELINO, F. L. C.; SANTOS, R. N. M.; PADOVANI, R. C. A inteligência competitiva aplicada à comunicação e à arquitetura da marca de uma organização. Bibliotecom, Florianopolis, p.47-58, jun. 2004. Disponível em: <https://periodicos.ufsc.br/index.php/eb/article/view/1518-2924.2004v9nesp1p47 /5280>. Acesso em: 27 abr. 2015.

NASCIMENTO, D. P.; NUNES, P.; BASTO, M. O valor da marca: Proposta do modelo Danrise. Remark, São Paulo, v. 10, n. 2, p.106-125, ago. 2011. Disponível em: <http://www.revistabrasileiramarketing.org/ojs-

2.2.4/index.php/remark/article/view/2258/pdf_60>. Acesso em: 16 mar. 2015.

OLIVEIRA, B. de et al. A importância da publicidade para uma empresa de serviços de saúde suplementar: Unimed Costa Verde. 2006. 58 f. TCC (Graduação) - Curso de Administração em Marketing, Faculdade Machado de Assis, Rio de Janeiro, 2006. Disponível em: <.famanet.br/ambientes/adm/pdf/mo_pub.pdf>. Acesso em: 31 mar. 2015.

OLIVEIRA, M. O. R. de; LUCE, F. B. O valor da marca: conceitos, abordagens e estudos no Brasil. Read, Porto Alegre, v. 17, n. 2, p.502-529, ago. 2011. Disponível em: <http:// www.scielo.br/scielo.php?script=sci_pdf\&pid=S1413$3112011000200008 \&$ Ing=en\&nrm=iso\&tlng=pt>. Acesso em: 15 mar. 2015.

OMPI; Organização Mundial da Propriedade Intelectual, 2003. Disponível em:

http://www.wipo.int/export/sites/www/freepublications/pt/sme/900/wipo_pub_900.pdf. Acesso em: 12 mar. 2015.

PADULA, M. Comunicação e o Cooperativismo Médico no Brasil: Um estudo de caso sobre o sistema nacional de saude Unimed. 2004. 15 f. TCC (Graduação) - Curso de Comunicação e Marketing, Faculdade Integrada Metropolitana de Campinas, Campinas, 2004. Disponível em:

<http://www.portcom.intercom.org.br/pdfs/17019513589693170290893172222824454882.pdf>. Acesso em: 31 mar. 2015.

PARISSOTTO, Giovanna Chaves. Vestir-se-para-ser e o consumo dos símbolos da imagem da marca pela comunicação visual na moda. 2011. 108 f. Dissertação (Mestrado) - Curso de Comunicação, Universidade Estadual de Londrina, Londrina, 2011. Disponível em: <http://www.bibliotecadigital.uel.br/document/?view=vtls000166570>. Acesso em: 31 mar. 2015.

PEREIRA, M. S.; CABRAL, J. E. de O. Determinantes de sucesso na implementação de programas de marketing relacionado a causas. Rege, São Paulo, v. 18, n. 1, p.111-127, mar. 2011. Disponível em: <https://goo.gl/hhcLhz>. Acesso em: 27 mar. 2015.

PEREIRA, S. R. V. Gestão Emocional da Marca: O caso Salsa. 2005. 168 f. Dissertação (Mestrado) - Curso de Ciências Empresariais, Universidade do Porto, Porto, 2005. Disponível em:

http://www.fep.up.pt/docentes/cbrito/Gest\%C3\%A3o\%20Emocional\%20da\%20Marca\%20\%200\%20caso\%20Salsa.pdf. Acesso em: 15 mar. 2015.

PIZZINATTO, A. K. et al. Efeito país de origem na avaliação de marcas de luxo: Um estudo experimental. Internext, São Paulo, v. 9, n. 2, p.94-109, ago. 2014. Disponível em: <http://marketingandrea.com.br/site/wpcontent/uploads/2015/02/internext.pdf>. Acesso em: 17 abr. 2015. 
RAMOS, H. F. S. A identidade da marca versus imagem: Caso Futebol Clube do Porto. 2013. 157 f. Dissertação (Mestrado) - Curso de Gestão Comercial, Fep - Universidade do Porto, Porto, 2013. Disponível em: <http://repositorioaberto.up.pt/bitstream/10216/70777/2/15652.pdf>. Acesso em: 15 mar. 2015.

RESENDE, A. A. P. de; GOMES, C. da S.; CARVALHO, W. Impacto da adoção das boas práticas de governança coorporativa na Unimed Volta Redonda. 2012. 43 f. Monografia (Especialização) - Curso de Gestão de Negócios, Fundação Unimed, Volta Redonda, 2012. Disponível em: <file:///C:/Users/pesquisa06/Documents/Downloads/ANDREIA APARECIDA PARENTE E CRISTIANE DA SILVA GOMES.pdf>. Acesso em: 31 mar. 2015.

SANT'ANA, V. de A. E se colocar pimenta? Análise semiótica da identidade da marca Chilli Beans. $2012.145 \mathrm{f}$. Dissertação (Mestrado) - Curso de Administração de Empresas, Pontifícia Universidade Católica, Rio de Janeiro, 2012. Disponível em: <http://www.maxwell.vrac.puc-rio.br/Busca_etds.php?strSecao=resultado\&nrSeq=19887@1>. Acesso em: 31 mar. 2015.

SAUNDERS, J.; GUOQUN, F. Dual branding: how corporate names add value. Journal of Product and Brand Management. New York: v. 6, n. 1, p.40-48, 1997.

SCHARF, E. R. O estilo de vida e a experiência: aspectos da marca no entendimento de seus usuários. Rbgn, São Paulo, v. 13, n. 38, p.99-113, mar. 2011. Disponível em: <http://dialnet.unirioja.es/ servlet/articulo?codigo=3673241>. Acesso em: 15 mar. 2015.

SCHITT, M. R. Marketing de relacionamento na Unimed grande Florianópolis: Avaliação da percepção do atendimento de novos clientes. 2007. 99 f. TCC (Graduação) - Curso de Administração, Universidade Federal de Santa Catarina, Florianópolis, 2007. Disponível em:

<https://repositorio.ufsc.br/bitstream/handle/123456789/131256/Adm292462.pdf?sequence=1\&isAllowed=y>. Acesso em: 31 mar. 2015.

SEMPREBON, E. et al. A importância da interdependência no relacionamento com marcas. Rege, São Paulo, v. 21, n. 4, p.561-577, dez. 2014. Disponível em: <http://regeusp.com.br/arquivos/2014.4.7.pdf>. Acesso em: 15 abr. 2015.

SILVA, G. G. O BRANDING: Ferramenta estratégica para o posicionamento da marca, 2007. Disponível em: http://fido.palermo.edu/servicios_dyc/encuentro2007/02_auspicios_publicaciones/actas_diseno/ articulos_pdf/A079.pdf. Acesso em: 15 mar. 2015.

SOUZA, I. L. de; LEÃO, A. L. M. de S. Dionísio usa Chilli Beans? Análise mitológica da publicidade da "Marca da Pimenta". Rac, Rio de Janeiro, v. 17, n. 5, p.574-597, out. 2013. O. Disponível em: <http://www.scielo.br/pdf/rac/v17n5/v17n5a06.pdf>. Acesso em: 31 mar. 2015.

TAVARES, F. Gestão de Marca: estratégia e marketing. Rio de Janeiro: E-papers Serviços Editoriais Ltda,2003. 276p.

TEH, C. C.; KAYO, E. K.; KIMURA, H. Marcas, patentes e criação de valor. Revista de Administração Mackenzie, v. 9 , n. 1, p. 86-106, 2008.

THOMAZ, J. C.; BRITO, E. P. Z. Reputação Corporativa: Construtos formativos e implicações para a gestão. Rac, Curitiba, v. 14, n. 2, p.229-250, abr. 2010. Disponível em: <http://www.scielo.br/pdf/rac/v14n2/v14n2a04.pdf>. Acesso em: 27 mar. 2015.

TOLEDO, L. A. A internet e o composto de marketing: Os casos Banco do Brasil e Unimed Seguros. 2007. 190 f. Tese (Doutorado) - Curso de Administração, Universidade de São Paulo, São Paulo, 2007. Disponível em: <http://www.teses.usp.br/teses/disponiveis/12/12139/tde-23012008-173121/pt-br.php>. Acesso em: 15 mar. 2015.

TRAVASSOS, C.; Martins, M. Uma revisão sobre os conceitos de acesso e utilização de serviços de saúde. Caderno de Saúde Pública, Rio de Janeiro, v.20 n. 2, p.190 -198, abr. 2004. Disponível em: http://www.scielosp.org/pdf/csp/v20s2/14.pdf. Acesso em: 01 mar. 2015.

TULESKI, Y. M. Tutorial: Marcas e Branding. 2009. Disponível em: http:// www.cedet.com.br/index.php?/Tutoriais/Marketing/marcas-e-branding.html. Acesso em: 15 mar. 2015.

VELOSO, A. R. Como medir a produtividade de Marketing da Empresa através dos conceitos de Valor de Marca e Lealdade à Marca. VI SEMEAD, 2003, São Paulo.

VERGARA, S. C. Métodos de pesquisa em administração. $5^{\mathrm{a}}$ ed. Rio de Janeiro: Atlas, 2005.

YANASE, M. H. Gestão de Marketing: avanços e aplicações. São Paulo: Saraiva, 2006.

YOUNES, S. D.; BRITO, E. Z. A influência da reputação do gestor na construção da identidade da empresa: um estudo de caso na Unimed do Brasil. 2009. 118 f. Dissertação (Mestrado) - Curso de Administração de Empresas, Universidade Presbiteriana Mackenzie, São Paulo, 2009. Disponível em: <http://tede.mackenzie.com.br/tde_arquivos/1/TDE-2009-0412T175715Z-693/Publico/Stephan Dualibi Younes.pdf>. Acesso em: 15 mar. 2015. 